\title{
Characteristics of Mudstone in Complex Fluvial Sedimentary System in Bohai L Oilfield
}

\author{
Kai Huang ${ }^{1}$, Chunsheng Shen ${ }^{1}$, Kai Kang ${ }^{1}$, Libing Wang ${ }^{1}$, Zhongbo Xu${ }^{1} \& \operatorname{Lin~Li}^{1}$ \\ ${ }^{1}$ Bohai Petroleum Research Institute, Tianjin Branch, CNOOC, Co., Ltd., China \\ Correspondence: Huang Kai, Bohai Petroleum Research Institute, Tianjin Branch, CNOOC, Co., Ltd., China. E- \\ mail: dr.superhou@163.com
}

Received: April 2, 2018

doi:10.5539/esr.v7n2p79
Accepted: April 16, $2018 \quad$ Online Published: July 9, 2018

URL: https://doi.org/10.5539/esr.v7n2p79

\begin{abstract}
Bohai L oilfield develops a complex fluvial sedimentary system, which includes many types of fluvial sedimentary facies. Based on the coring well of oil field, the distribution characteristics of mudstone are analyzed, it is shown that the mudstone has similar internal structure and can be classified into four types according to its color: gray to grayish, variegated, brown to gray-brown and khaki, the assemblage has a large gray to grayish mudstone section, large gray to grayish mudstone intercalated thin layer sandstone, gray to grayish mudstone associated with variegated (brown) mudstone, grayish mudstone associated with lacustrine sand grain bedding sandstone, concomitant generation of large staggered bedding sandstone and grayish mudstone, mixed (gray-brown) mudstone associated with large staggered bedding sandstone, interaction between different colors of mudstone and sandstone and large interlaced sandstone intercalated with thin layer mudstone. The mudstone color is mainly gray and grayish, and very few oxidized mudstone is developed alone, which indicates that fluvial mudstone may be formed in the reductive environment in humid climate, and the fluvial mudstone in this area may be formed in the oxidizing environment, which is different from the general understanding of fluvial facies, the oxidation color is the result of the later transformation.
\end{abstract}

Keywords: complex fluvial system, mudstone color, mudstone genesis, Bohai Bay Basin

\section{Introduction}

It is generally considered that mudstone varies greatly in different backgrounds and can be used to indicate sedimentary environment. Such as in the reducing environment and deep water environment, there are differences in the color of mudstone, bedding and organic matter content, there are also differences in sonic time difference curve, density curve and even seismic, so that different sedimentary environments can be distinguished. However, in complex fluvial systems, mudstone characteristics are not obvious, so it is difficult to distinguish different sedimentary environments, especially different mudstones, which have similar sedimentary internal structure and composition, but have no obvious difference except color, so it's very difficult to identify the sedimentary environment. It is generally believed that the fluvial system is developed in the water environment, and the mudstone should be characterized by oxidation, such as brown, red and so on. At the same time, paleosols are often developed because of the exposure to the land environment. A large number of outcrop observations have also confirmed this understanding. However, the core observation of continuous coring section in L Oilfield shows that the fluvial sedimentary system is not so simple, and its interior may be composed of complex sedimentary systems by various environments, including fluvial facies, inter fluvial depressions, lakes, etc, a combination of delta and interfluvial flood plains, not just fluvial systems. The mudstone in this system may be different from our original understanding, it is deposited in a reductive environment, but it may eventually manifest itself in an oxidizing or reducing environment, which is controlled by the syngenic environment after its deposition, in different syngeneic environment performance for different characteristics.

\section{Mudstone Characteristic}

Study of mudstones in the research area indicated, the mudstones in the complex fluvial system are different from the lacustrine mudstones or swamp facies mudstones, which are highlighted by the following characteristics:

\subsection{Impure Argillaceous}

The mudstone looks rough on the whole, and the section is not tidiness and has no luster. Contains silt, sometimes 
sand or gravel, with some mixed features. In general, the cementation is not tight, and loose parts are mostly powdery or irregular.

\subsection{Massive Bedding Features}

Basically, it is not developed bedding for rapid depositing, mainly in massive. The internal heterogeneity is poor and basically has similar structural characteristics, indicating that the sedimentary environment is similar or identical. It may be a result of rapid sedimentation. In particular, some of the gravels in the sand-bearing or pebbly segments show dispersion, indicating rapid accumulation process.

\subsection{Low Organic Matter Content}

The observation of its appearance indicates that it does not have obvious ,residue of carbon-based nor does it develop a dense structure that is rich in dispersed organic mudstone. Judging from the results of its electrical measurements and interpretations, the differences between the sonic time difference and the density log curve of mudstone are not obvious, and it also suggests that the organic matter content is not very different. Oxide-colored mudstone apparently does not have a rich organic matter content, while mudstone with a reduced color does not have a significant difference from it, suggesting that it has a similarly low organic matter content.

\subsection{Few Cuttings or Roots Structures}

In mudstone, there are basically no charcoal or plant root traces, suggesting that they were deposited in non-marsh or shore environments, and may be the result of rapid underwater sedimentation. The plants did not have time to grow, and there were not a large number of plants that were brought into the mudstone. The water power is weak and it does not have the ability to carry plant debris.

\subsection{Rare Deformation Structure}

The mudstones are basically distributed continuously. Scoured boulders are rarely seen in contact with sandstones, and there are almost no deformed structures such as deformed or torn mudstones. These indicate that the bottom shape of the mudstone is relatively stable and may not have a gradient, and there is no comparison. The apparent need for rapid water release indicates the relative stability of its mudstone deposition environment.

The mudstone structure in the study area has a small difference, but the color difference is obvious. Based on the color, it can be divided into four categories:

The first type is gray to grayish. Such mudstones are dominated by grayish, which may develop in large sections or coexist with sandstone. The shades of color are different, but basically they all show the characteristics of reduced color, indicating that they are formed in the reducing environment and have not undergone the later reformation.

The second type is brown to khaki mudstone. Such mudstones are structurally denser than the first types of mudstones, and may be the result of strong cementation. They exhibit blocky characteristics, and the internal colors are not very uniform, sometimes with patches of different colors. This type of mudstone and gray mudstone show a transitional contact pattern, which can be a continuous transition from gray to dark purple to brown, indicating that it may be formed by the later oxidation of grayish mudstone.

The third type is khaki mudstone. It shows obvious characteristics of soil gasification, appears loose, sometimes presents a mixture of khaki and gray, sometimes shows a mixture of khaki and brown, and is a sign of ancient soil, indicating that it has undergone a long period of weathering and soiling.

The fourth category is variegated mudstone. Mudstones are of mixed colors ranging from violet-brown to khaki, grayish to gray-brown, showing a transition between different types of environments, which is the result of incomplete changes in the original mudstone environment in the later period and direct evidence of late environmental changes.

\section{The Combination Style of Mudstone}

\subsection{Large Set of Gray to Grayish Mudstone Section}

This type of mudstone exhibits large-scale continuous production characteristics. The thickness of a single layer is several meters. The thickest part of the coring well reaches nearly 10 meters, such as 6 wells 1145-1153 meters. This section is a continuous mudstone section about 8 meters thick, in addition to individual parts of the color has changed, basically gray to grayish, of course, some changes in the color also appeared small differences in structure, such as the partial display of looser features, the other parts are relatively dense. Locally dispersed, khaki, porphyritic crumb exhibit weak post-modification. Another example is the 6 well 1399-1401 meters well section, the upper part is relatively loose grayish, and the lower part is to show some light purple features with grayish- 
based slightly oxidized transformation characteristics (Figure 1A). This grayish mudstone should be formed in shallow water environments that are stable for a long period of time. It is only during the flood season that muddy materials are carried along with the water, and there is usually less sediment supply. At the same time, it is basically not exposed to air, and oxidation color characteristics are rarely seen.

\subsection{Large Sections of Gray to Grayish Mudstone Sandwich thin Layered Sandstone}

This shows a large section of grayish mudstones with small layers of parallel bedding or massive bedding sandstones. Mudstones and the surface of sandstones show abrupt contact, but mudstones are less likely to be cracked and no boulder clay is found (Figure 1E, 2A). The color of mudstone is changed, and above or below the sandstone, there may be changes in the purity and color of the mudstone as a result of deeper or shallower water bodies or changes in sediment supply. This type of combination is similar to the former type and is formed in a long-term stable shallow water environment. However, due to the relatively strong hydrodynamic forces, floodwaters carry sand into the water from time to time to form short-term thin sand deposits.

\subsection{Grayish Mudstones Associated with Variegated (Brown) Mudstones}

The variegated (brown) mudstones are associated with the top or bottom, and the ratio of mudstones of different colors is also different. There may be a mixture of grayish mudstones with variegated mudstones, brown mudstones or khaki mudstones. The mixing ratio indicates the size of the layer to be modified, and the degree of color mixing reveals the strength of the transformation. The 1039-1039.5 $\mathrm{m}$ of the 1D Figure shows a yellowish color, while the other parts are grayish, indicating that the sediment has undergone a deep soil transformation and the characteristics of the upper mudstone soil are relatively obvious. However, the formation of the mudstone is not a continuous exposure transformation. Affected intervals are relatively limited. In Figure 2C, the mixed color is different from the former, the mixed colors are mixed, and the mixed color layer is thick, but the mixed color oxidation degree is not very high, and may be related to the intermittent exposure and renovation of the mixed color for a long time. This transformation generally takes a long time, but the time for a single-stage transformation is not long, making the transformation not very serious and without the characteristics of soilization, but the large-scale mudstones are transformed by oxidation. During the transformation process, the degree of transformation of different intervals is different, and different parts of the original color are retained in different parts. Part of the 1416-1416.5m section of the Figure 2D was reconstructed obviously. It has certain characteristics of soilization, indicating that it has a relatively high degree of transformation, but it has also been slightly modified at the site of 1417.2 meters. The original sedimentary features have been preserved in other parts.

\subsection{Grayish Mudstones Associated with Lake-Phase Sand-Grain Sandstone}

The $1166.5-1167 \mathrm{~m}$ grayish mudstone in the Figure let $1 \mathrm{~F}$ is associated with the upper layer of wave sand pattern, which indicates that the sediment has some lake energy and reveals the existence of the lake.

\subsection{Large Interlaced Sandstones Associated with Grayish Mudstones}

The lower part of the Figure 2B is mudstone, and the upper part is a large cross-stratified sandstone. The upper part is a distributary channel or fluvial channel deposition, while the lower part of the mudstone is deposited in shallow water bays or depressions. There is a significant abrupt contact between the two, and there may be a scouring surface, but no mudstone is found, indicating that the sediment is under water. The volcanic mudstone does not have strong scouring effect, but is mainly a kind of filled sand filling effect.

\subsection{Variegated (Grey-Brown) Mudstones Associated with Large Interlaced Sandstones}

The lower part of the Figure 1C is a large-scale cross-bedded sandstone, while the upper part is a brown mudstone reconstructed with a thin layer of grayish mudstone at the bottom of the mudstone. After the deposition, it was later exposed and reformed to form an oxidized mudstone section.

\subsection{Mudstones of Different Colors Interact with Sandstone}

As shown in Figure 1G and 2E, mudstones of different colors form interactive deposits with sandstones. In the Figure 1G, the sandstone from the lower part transitions upwards into the shaly sandstone and mudstone, and then the oxidized mudstone finally turns into the earthy yellow mudstone with obvious soilization. Mudstone is obviously a different sediment in the third stage, and its formation process is also different. The top mudstone modification is obviously higher than the lower part. In the Figure 2E, the previously deposited mudstone was oxidized and soiled, and then converted to shallow muddy sedimentary sedimentary mudstone, which was then converted into a sand body with strong hydrodynamics and fluvial deposit environment.

\subsection{Large Sets of Large Interlaced Sandstones with thin Layers of Mudstone}

This type of mudstone is a muddy deposit caused by the interruption of sand supply during fluvial sedimentation 
and can be used as a sandwich in sandstone (Figure 2F, 2G). Mudstone contains a certain amount of sand, showing horizontal bedding features. From the color point of view, it is mainly grey, indicating that even in the fluvial environment, the original sedimentary mudstone may be a reduction color.

\section{The Spatial Evolution Characteristics of Mudstone}

The observation of the core well shows that the development of mudstone has the following characteristics:

Mudstone changes quickly. There are obvious changes in different horizons and between different locations in the same period. The change of mudstone is mainly reflected in the change of thickness and color, especially the change of color is particularly large. In the same interval or in different spatial positions of the same interval, the color of mudstone will change greatly, indicating the environment after deposition is not particularly stable, and the exposure is a common phenomenon. However, there are also differences in this exposure. Sometimes it is a continuous exposure for a long time, resulting in soil erosion. Sometimes it is only intermittent intermittent exposure. It causes mudstone to show oxidation color characteristics.

The variegated or khaki mudstones rarely appear on their own, and are often associated with gray to grayish mudstones. The observation of Mudstone shows that the development of oxidized mudstone seldom occurs on their own. Even a large section of variegated mudstones are mixed with small grayish mudstones. This may indicate that the oxidation of the environment is based on reduced deposition, and there is no direct deposition of mudstone in oxidizing environment. For example, there are 1218.7-1225.75m mudstones in No. 6 wells with variegated mudstones and paleosol muds, but there are also multiple grayish mudstone sections in the middle. Although the grayish mudstone segments are mostly below $20 \mathrm{~cm}$, they are indistinguishable from those of variegated mudstones and soil muds, suggesting the interval characteristics of sedimentation and exposure (Figure 3).

The mudstone associated with small layered rocks or associated with thin sandstones is mostly grayish. There is little interaction between gray mudstone and small sandstone segments.

The mudstone is mainly gray to grayish, rather than brownish or variegated oxidized color. The statistical results of mudstone sections observed on the core of the area indicate that the proportion of oxidized mudstones such as brown and variegated is low, and the thickness of a single section is not large. And mudstone is mainly composed of reduced mudstone. The total thickness of grayish mudstone in the 4 wells is 82.6 meters, accounting for $87 \%$ of the total; and the grayish rock in the 6 wells is 45 meters, accounting for 73\%.The well 8 has 19.9 meters of grayish rock, accounting for $80 \%$ of the total, and the PL25-6-3 has 22.5 meters of grayish rock, accounting for $84 \%$ of the total. On the other hand, grayish mudstone also predominates in terms of the number of layers and the thickness of the monolayer (Table 1).

Table 1. Development Characteristics of Mudstone with Different Colors

\begin{tabular}{llcccc}
\hline Well Name & & Well 4 & Well 6 & Well 8 & Well 3 \\
\hline \multicolumn{2}{l}{ The total length (m) } & 94.9 & 61.5 & 24.9 & 26.8 \\
Grayish & Number of plies & 65 & 40 & 22 & 28 \\
& $\begin{array}{l}\text { Maximum thickness of } \\
\text { single layer (m) }\end{array}$ & 6.3 & 9.2 & 5.2 & 7.6 \\
& $\begin{array}{l}\text { Average (m) } \\
\text { Taupe }\end{array}$ & 1.3 & 1.1 & 0.9 & 0.8 \\
& Number of plies & 0 & 6 & 2 & 1 \\
& $\begin{array}{l}\text { Maximum thickness of } \\
\text { single layer (m) }\end{array}$ & 0 & 1.3 & 0.6 & 1 \\
& Average (m) & 0 & 0.6 & 0.4 & 1 \\
\multirow{5}{*}{ Wheat } & Number of plies & 4 & 8 & 3 & 2 \\
& $\begin{array}{l}\text { Maximum thickness of } \\
\text { single layer (m) }\end{array}$ & 1.3 & 2.4 & 1 & 0.8 \\
& Average (m) & 0.7 & 0.8 & 0.5 & 0.6 \\
Mottle & Number of plies & 1.2 & 12 & 8 & 7 \\
\hline
\end{tabular}




\begin{tabular}{lcccc}
\hline $\begin{array}{l}\text { Maximum thickness of } \\
\text { single layer (m) }\end{array}$ & 13 & 2.4 & 0.6 & 0.8 \\
Average (m) & 0.7 & 0.8 & 0.3 & 0.3 \\
\hline
\end{tabular}

\section{Discussion on Relationship between Mudstone Development and Sedimentary Environment}

In case of $\mathrm{L}$ oilfield, mudstone mainly reflects the reduced color of gray to grayish in the complex fluvial system. Although there are variegated mudstones and even soiled paleosol, they are not dominant. The assemble pattern of mudstone and distribution show that few mudstones of oxide color exist alone. They probably formed in the reducing environment, then syngenetic environment changed their original color, or the final color was changed by syngenetic environment. There is no trace of plant growth or deposition in the mudstone, which indicates that this kind of mudstone deposit is different from the fluvial bay environment where plant debris easily accumulates and environment with plant growth.

The characteristics of this mudstone are obviously different from the fluvial environment which we recognize as characterized by exposure and soilization. It may indicate that the fluvial facies is not necessarily what we originally considered to be the product of the exposed environment, but it may be the interaction between the reducing environment and the exposed environment. And the mudstone deposits may also be mainly developed in low-lying areas or lakes, but not by fluvial flows over the arid fluvial plain. Perhaps the formation of mudstone in $\mathrm{L}$ oilfield is related to its location and climate. Humidity has a large number of small lakes and puddles and wetlands, which has a large number of local depocenter and small catchment area and fluvials are in the low-lying land. There are a large number of lakes and wetlands between fluvials, but only the local outcropped area is oxidized, or shows the oxide color for soilification. The L oilfield is located in the catchment area or the extinction zone that is closer to the middle of the lake basin and has some characteristics of lacustrine sedimentary. Under the background of arid environment, the characteristics of mudstone with oxide colors may develop.

\section{Conclusion}

The core observation shows that the internal structure of mudstone is almost the same. But from the color, it can be divided into four types: grayish mudstone with reduced colors, brown-beige of mudstone with shallow change, the the yellow mudstone with soilification and variegated mudstone.

According to the distribution pattern of mudstone, eight types of mudstone assemblage were summarized, and the formation process was related to the sedimentation of mudstone and later oxidation.

In L oilfield complex fluvial system, mudstone is manly with reduced colors rather than with oxide color, which shows that mudstone originally formed in reducing environment, and oxide color caused by the late synsedimentary environmental reconstruction.

\section{Acknowledgements}

This research work was funded by Major Projects of National Science and Technology "Bohai oilfield infill adjustment and enhanced oil recovery reservoir engineering technology demonstration” (Grant No. 2016ZX05058001-002).

\section{References}

Gao, Zh. Y., Han, G. M., \& Zhang, L. H. (2007). Parasequence of fluvial deposit a case study of the Xujiahe Formation in Central Sichuan.Oil and Gas Geology, 28(1), 59-68.

Li, F. L., Qu, X. Y., Liu, L., Yang, D. M., Wang, D. H., \& Zhao, G. X. (2009). Sedimentary environment on upper Permian Linxi Guoup in Inner Mongolia. Acta Sedimentologica Sinica, 27(2), 265-272.

Li, X. H., Chen, S. D., \& Cao, K., et al. (2009). Paleosols of the mid-Cretaceous: Areport from Zhejiang and Fujian, SE China. Earth Science Frontiers, 16(5), 63-70.

Liang, D. G., Guo, T. L., Chen, J. P., Bian, L. Z., \& Zhao, Zh. (2008). Distribution of Four Suits of Regional. Marine Source Rocks Marine Origin Petroleum Geology, 13(2), 1-15.

Ni, Ch. H., Zhou, X. J., Wang, G. Sh., Liu, Y. L., \& Yang, F. (2011). Sedimentary environment and geochemical characteristics of hydrocarbon source rocks in the Pingliang Formation, southern margin of the Ordos Basin. Oil and Gas Geology, 32(1), 38-46.

Xu, J., Pu, R. H., Yang, L., \& Li, A. H. (2010). The palaeosalinity analysis of carboniferous mudstone, Tarim Basin. Acta Sedimentologica Sinica, 28(3), 510-517. 
Yang, F., \& Jia, J. H. (2006). Alluvial fan and fan-delta sedmientary facies and favorable assemblage of reservoir and seal of Wushi Sag (Cretaceous) in Tarim Basin. Acta Sedimentologica Sinica, 24(5), 681-682.

Yang, L. Sh., Chen, B. T., Li, \& Sh. L., et al. (2013). Pattern of genesis-based mudstone distribution for sandy braided river: A case study of sandy braided-river outcrop, Datong, Shanxi province. Natural Uas Ueoscience, 24(1), 93-98.

Ye, L. M., Qi, T. J., \& Peng, H. Y. (2008). Depositional environment analysis of Shanxi formation in eastern Ordos Basin. Acta Sedimentologica Sinica, 26(2), 202-209.

Zhang, Ch. M., Zhang, W. Sh., \& Guo, Y. H. (2012). Sedimentary environment and its effect on hydrocarbon source rocks of Longmaxi Formation in southeast Sichuan and northern Guizhou. Earth Science Frontiers, 19(1), 136-145.

\section{Appendix}
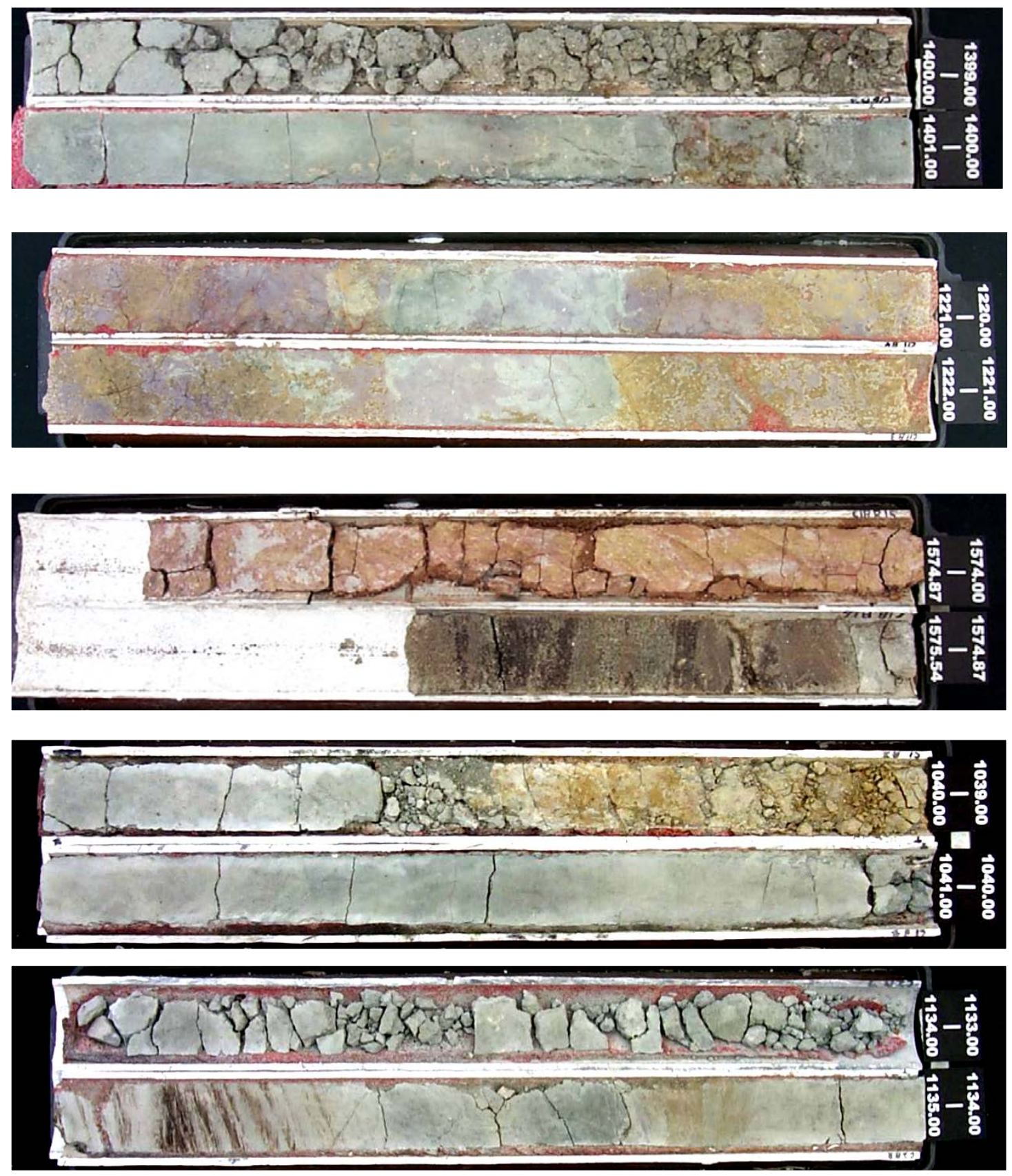

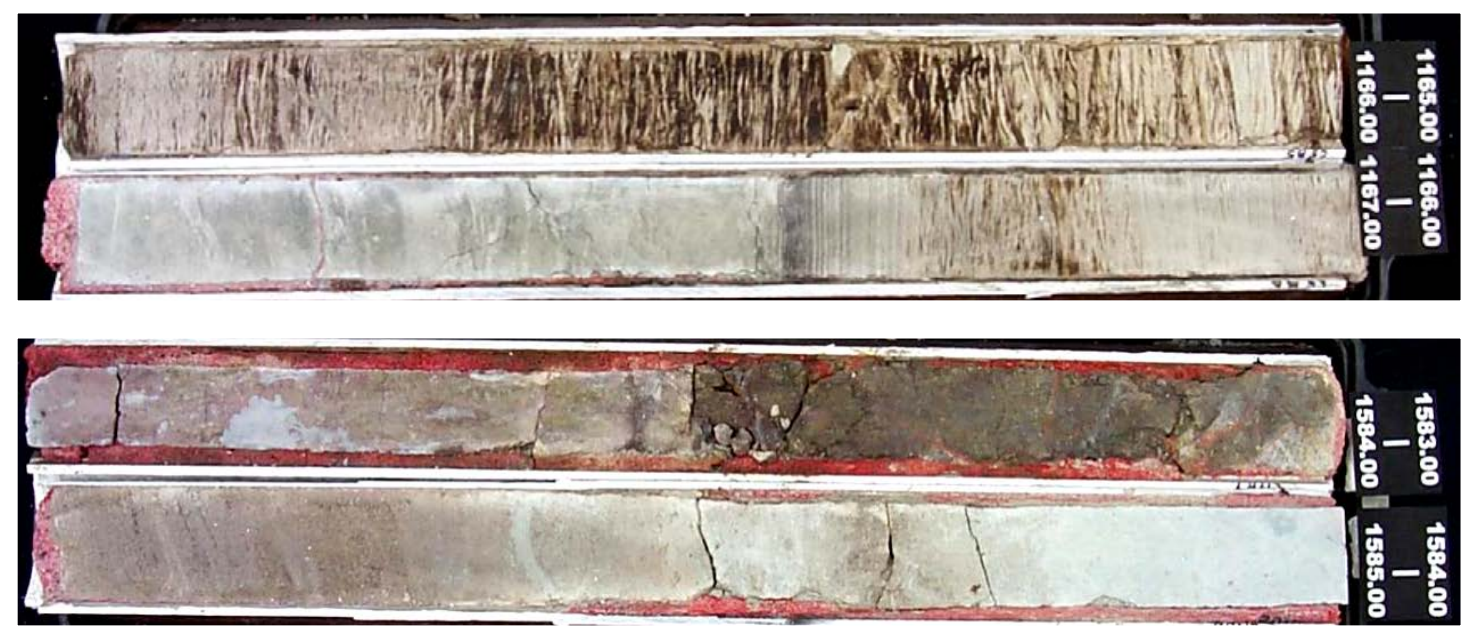

Figure 1. Core section of 6 wells, arranged in order of A, B, C, D, E, F, G
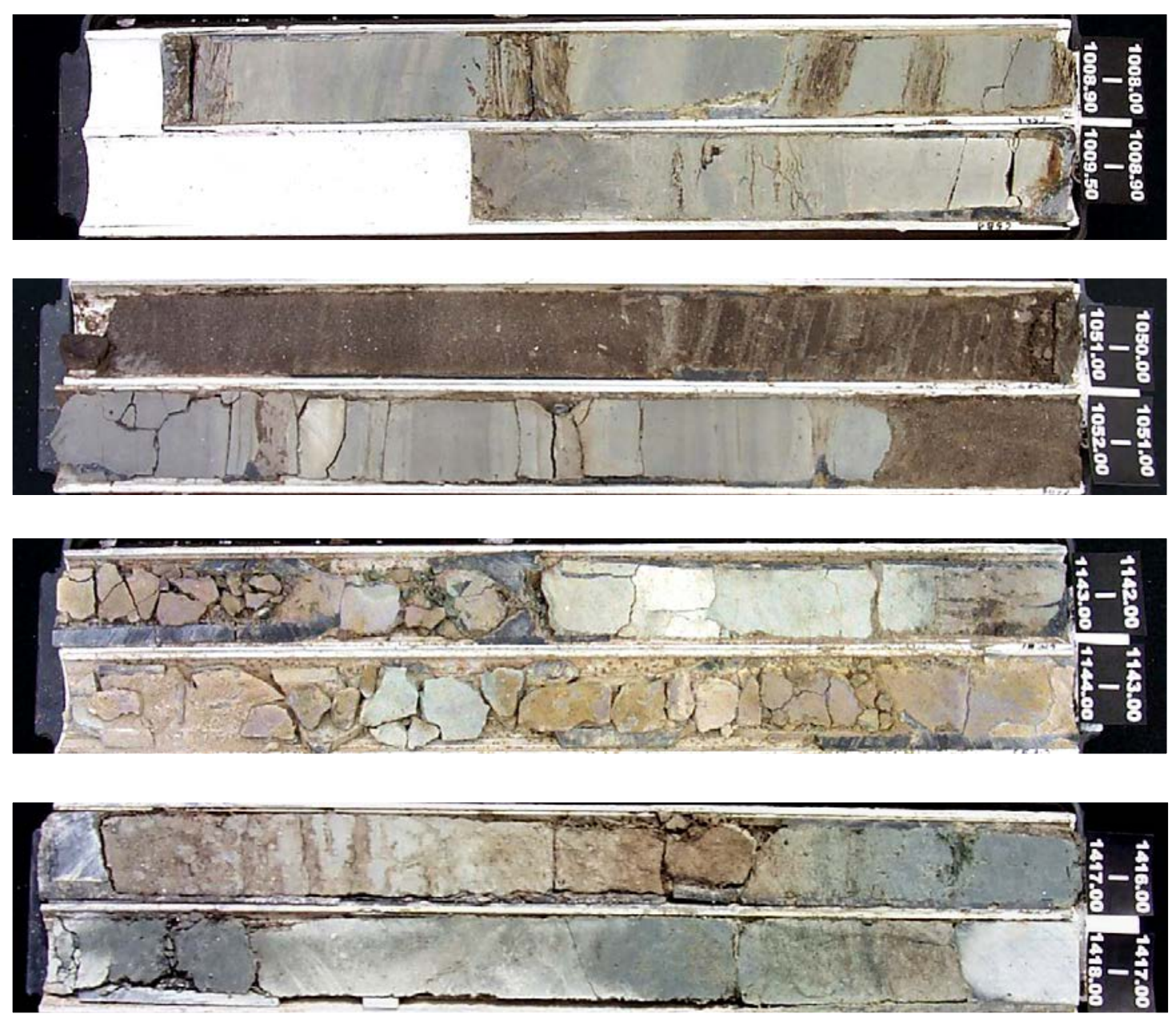

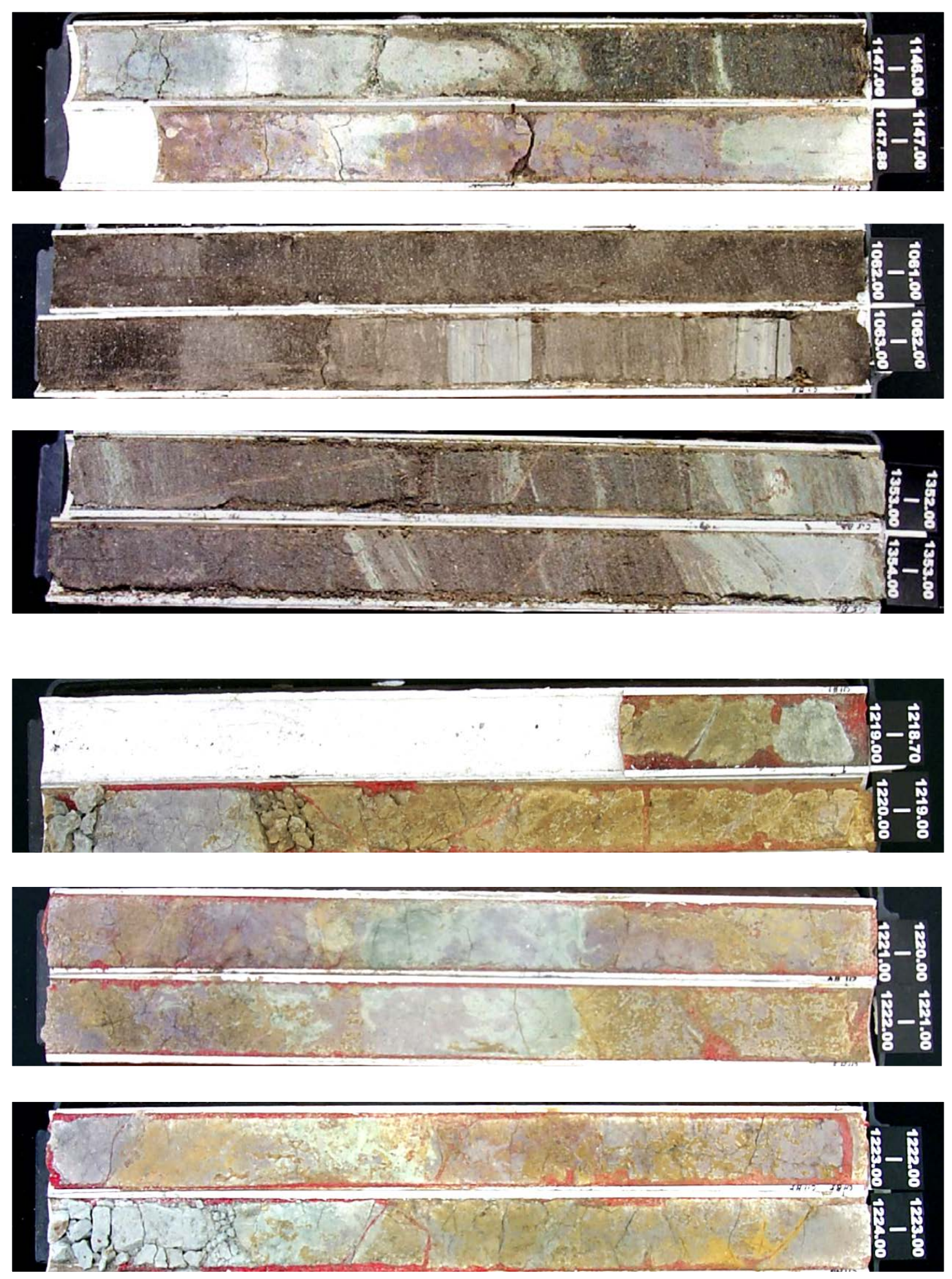

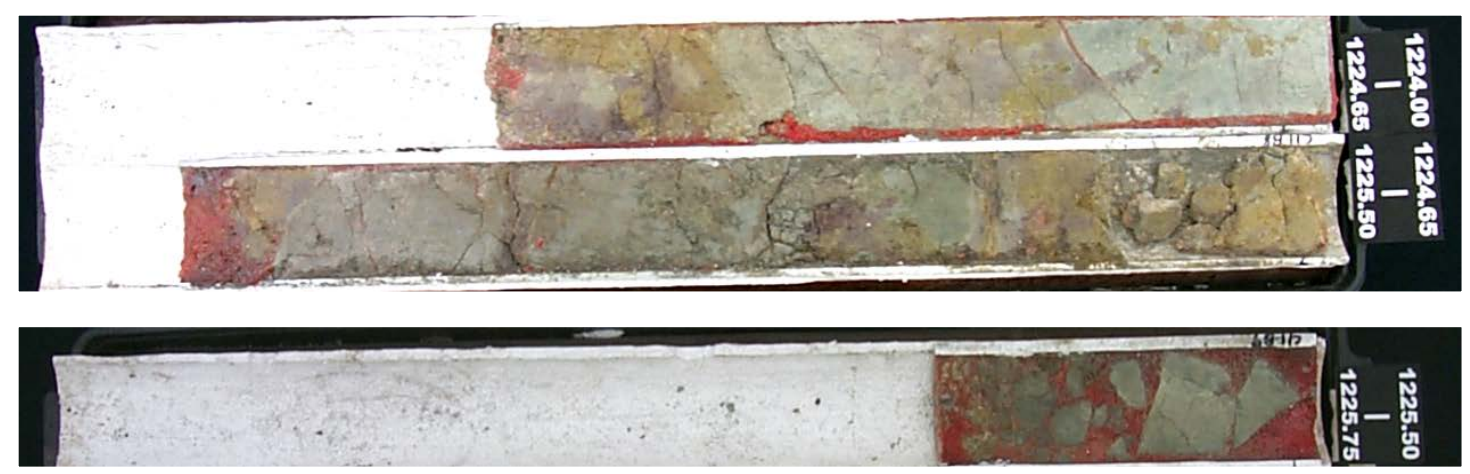

Figure 2. Core section of 8 wells, arranged in order of A, B, C, D, E, F, G, H, I, J, K, L

\section{Copyrights}

Copyright for this article is retained by the author(s), with first publication rights granted to the journal.

This is an open-access article distributed under the terms and conditions of the Creative Commons Attribution license (http://creativecommons.org/licenses/by/4.0/). 